\title{
DESEMPENHO DE VARIEDADES DE MILHO QUANTO À QUALIDADE DA PALHA PARA ARTESANATO
}

\author{
FLAVIA FRANÇA TEIXEIRA ${ }^{1}$, JOSÉ HEITOR DE VASCONCELLOS ${ }^{1}$, RAMIRO VILELA DE \\ ANDRADE $^{1}$, MANOEL XAVIER DOS SANTOS ${ }^{1}$, DEA ALÉCIA MARTINS NETTO ${ }^{1}$, ETELVINO \\ HENRIQUE NOVOTNY $^{1}$ e MARCIO ANTONIO RESENDE MONTEIRO ${ }^{1}$
}

\begin{abstract}
${ }^{1}$ Embrapa Milho e Sorgo - Rod MG424 Km 65 - C.P. 151 - Sete Lagoas - MG - CEP 35701-970 flavia@cnpms.embrapa.br
\end{abstract}

Revista Brasileira de Milho e Sorgo, v.6, n.1, p.84-94, 2007

\begin{abstract}
RESUMO - O artesanato de palha de milho tem se tornado uma alternativa de renda para comunidades rurais, gerando demanda por atender cultivares que resultem em palha com padrão apropriado para o artesanato. O objetivo deste trabalho foi avaliar acessos do Banco de Germoplasma de Milho quanto a caracteres relacionados à palha. Foram avaliados 30 acessos provenientes do Banco de Germoplasma de Milho e testemunhas. As avaliações foram realizadas em duas safras: 2002/2003, em Diamantina e Cipotânea, e 2003/2004, em Diamantina e Paraopeba. Foram avaliados os seguintes caracteres: altura de plantas, produção e número de espigas, comprimento, cor e textura da palha. Os acessos avaliados apresentaram plantas altas, tornando-os muito suscetíveis ao acamamento. A avaliação da produtividade foi muito prejudicada, devido ao ataque de pássaros. O acesso MGIII apresentou espigas com palha longa. Quanto à coloração, destacaram-se os acessos BA093, MS003, SC012, SC015 e MGIII, em virtude de apresentarem palha clara, e o acesso MG053, pela alta pigmentação na palha. Além da divergência entre os acessos, foi observada variação entre indivíduos quanto à intensidade de pigmentação da palha, especialmente nos acessos MG092, MG053 e BA100. A avaliação da textura da palha, devido a sua subjetividade, foi associada a altos coeficientes de variação e a altas probabilidades de F. Não foram estimadas interações significativas entre tratamentos e locais, para altura de planta e comprimento de espiga. Os coeficientes de determinação genotípica estimados apresentaram valores elevados, indicando o potencial da seleção com base na manifestação fenotípica. Foram estimadas elevadas variâncias dentro das populações, indicando a possibilidade de sucesso com a seleção intrapopulacional.
\end{abstract}

Palavras-chave: Zea mays, agricultura familiar, melhoramento participativo.

\section{EVALUATION OF MAIZE VARIETIES FOR HUSK QUALITY FOR HANDCRAFT USE}

\begin{abstract}
Handcrafts made with corn husks have become an extra income for rural communities. The need of those communities for maize cultivars with husks that are suitable for use in this craft has determined the objective of this paper, which aimed to evaluate maize cultivars available from the Maize Germplasm Bank and testimony from witnesses. The evaluations were carried out during two different harvest seasons: 2002/
\end{abstract}


2003 in the cities of Diamantina and Cipotanea, and 2003/2004 in the cities of Diamantina and Paraopeba. The following characteristics were evaluated: plant height, yield and number of ears, and also length, color and texture of the husk. The varieties generated tall plants, which made them very susceptible to lodging. The variety MGIII presented ears with longer husks. Regarding coloration, the varieties BA093, MS003, SC012, SC015, and MGIII were distinguished by light-colored husks, the variety MG053 for high pigmentation of the husk. Besides the divergence between accessions, the husk color variability among individual plants was also present, especially for MG092, MG053 and BA100. The texture subjective analysis generated low-precision results. Because of its subjectivity, evaluations for this characteristic as associated with high coefficients of variation and high probabilities of F. Interactions between locations and treatments were not significant for plant height and length of the ear. High estimates for genotypical determination indicated potential of selection based on the phenotypical manifestation. High variances were estimated between plants in the population, suggesting the possibility of success with the intrapopulational selection.

Key words: Zea mays, smallholder producers, participatory breeding.

$\mathrm{O}$ artesanato de palha de milho tem se tornado uma importante alternativa de fonte de renda para diversas comunidades rurais, especialmente no Estado de Minas Gerais nos municípios de Diamantina, Cipotânea, Goianá e Paropeba. Bonecas, cestos, móveis trançados e outros produtos feitos com a palha do milho têm contribuído para o incremento do artesanato rural como atividade lucrativa e despertado o interesse de empresas dispostas a comercializar esses produtos nos mercados interno e externo (Mil, 2003; Arte, 2003; Canal Rural, 2003).

Ao surgir o interesse pelo uso da palha de milho em artesanato, ampliam-se as possibilidades de renda para o agricultor, pois, além da colheita de grãos, a palha pode ser usada por sua família para a produção de peças ou, mesmo, produzida visando à sua comercialização para outros artesãos.

A Embrapa Milho e Sorgo mantém o Banco Ativo de Germoplasma de Milho (BAG Milho), que visa suprir os programas de melhoramento e manter a variabilidade genética da espécie. As suas atividades principais são: conservação a curto e médio prazos, caracterização, avaliação, coleta, intercâmbio e documentação do germoplasma. O BAG Milho conta com 3.804 acessos de Zea mays L. e quatro acessos de parentes próximos do milho. Cerca de $65 \%$ do Banco de Ativo Germoplasma de Milho já se encontra caracterizado, seguindo os descritores preconizados por CIMMYT (1991) para a cultura do milho (Andrade et al., 2001). Porém, os caracteres relacionados à palha, relevantes para o artesanato, não constam da lista de descritores do milho.

Os acessos do BAG Milho possuem variabilidade para diversos caracteres, entre eles, a palha de milho (Teixeira et al., 2003). Para que essa variabilidade seja efetivamente empregada, é necessário identificar acessos que apresentem espigas longas, com palha macia e de coloração variada, e melhorar essas populações quanto aos caracteres relacionados com o desempenho agronômico, especialmente quanto à produtividade $\mathrm{e}$ percentual de acamamento, visando aliar qualidade de palha a boa performance agronômica.

A maioria das cultivares melhoradas foram desenvolvidas visando ampla adaptação 
ambiental e a satisfação das exigências da maioria dos consumidores e agricultores. Por essa razão, necessidades de certos segmentos que demandam caracteres especiais não podem ser atendidas quando é empregado o modelo de melhoramento clássico. Visando contornar essa limitação, utiliza-se o melhoramento participativo, que se baseia num conjunto de métodos que envolvem a colaboração entre pesquisadores e produtores para atuar em setores que não despertam o interesse de programas de melhoramento comerciais, em ambientes caracterizados pela agricultura de subsistência, em situações em que as condições ambientais são muito específicas, levando à exigência de um programa de melhoramento para uma pequena região ou em que os usuários necessitem de caracteres incomuns ou combinações desses caracteres (Morris e Bellon, 2004).

O modo de atuação do produtor e do pesquisador no melhoramento participativo é variável, podendo ser adotado desde o modelo em que os produtores participam apenas da avaliação final de variedades, cabendo ao melhorista definir os objetivos do trabalho, selecionar germoplasma, identificar caracteres-alvo, determinar a metodologia a ser adotada, testar e selecionar variedades nas estações experimentais, até o modelo em que os pesquisadores treinam os produtores a conduzir suas variedades locais, de forma a preservar os caracteres de interesse, eliminar caracteres indesejáveis e/ou introduzir novas fontes de variação e os produtores, treinados, executam a seleção, sem a supervisão do melhorista (Morris e Bellon , 2004).

O objetivo deste estudo foi avaliar, em comunidades rurais, com o auxílio de artesãs, acessos do BAG Milho e cultivares comerciais quanto aos caracteres relacionados à palha para artesanato, visando agregar informações ao Banco de Germoplasma de Milho e o emprego des- sas informações em programas de melhoramento participativo.

\section{Material e Métodos}

Para a avaliação da palha do milho para artesanato, foram selecionados 30 acessos do BAG Milho, coletados em diversas regiões do Brasil, em expedições realizadas entre as décadas de 50 e 70. Esses acessos foram identificados pelo confronto das necessidades das artesãs em relação ao tipo de palha de milho ideal para uso em artesanato com as características descritas nas fichas de coleta dos acessos. As testemunhas foram variedades locais cultivadas pelas artesãs, variedades comerciais cultivadas nas regiões onde foram conduzidas as avaliações e/ou híbridos comerciais lançados recentemente.

Os acessos foram avaliados, preliminarmente, em Diamantina-MG e Cipotânea-MG, na safra de 2002/2003, semeadura em outubro de 2002, com o objetivo de caracterizar as variedades testadas quanto a caracteres relacionados à palha, uma vez que essas características não são consideradas como descritores do milho (cimmyt, 1991). A avaliação preliminar foi realizada por meio de unidades de demonstração, com estande de 200 plantas por variedade.

Após essa avaliação preliminar, foram selecionadas dez variedades de melhor desempenho, quanto aos caracteres relacionados à palha do milho, para a segunda avaliação, realizada nos municípios de Diamantina - MG e Paraopeba - MG. Na segunda avaliação, com semeadura em novembro de 2003, foi empregado o delineamento de blocos casualizados com três repetições e parcelas experimentais de quatro linhas de quatro metros, com cinco sementes por metro linear. As testemunhas da segunda avaliação foram o híbrido duplo BRS2020 e, em Diamantina, uma variedade local. Os tratos cultu- 
rais, irrigação e adubação de cobertura foram os usuais de cada localidade.

$\mathrm{Na}$ avaliação preliminar, foram consideradas a produtividade total de espigas com palha, número total de espigas produzidas, comprimento de espigas, intensidade de cor de palha e textura de palha. Os caracteres comprimento de espigas e a intensidade da cor da palha foram avaliados em 60 plantas, enquanto, para os demais, os dados foram tomados considerando o desempenho médio das parcelas. Na segunda avaliação, além dos caracteres mencionados, foi considerada também a altura de planta, que foi mensurada em dez indivíduos por parcela, enquanto o comprimento de espigas e a intensidade de cor de palha foram tomados de 20 plantas por parcela; os demais caracteres foram anotados no nível total de parcelas.

A intensidade da cor da palha foi avaliada mediante escala de notas variando de 1 a 9, sendo a classificação feita em duas etapas. $\mathrm{Na}$ primeira, a palha foi classificada como escura, intermediária ou clara e, na segunda etapa, as espigas foram classificadas dentro de cada grupo, de acordo com a intensidade de pigmentação, permitindo melhor discriminação de pequenas diferenças quanto à intensidade da coloração. A textura da palha foi avaliada por, no mínimo, três artesãs, independentemente. As artesãs foram orientadas a avaliar com as mãos a textura da palha de cada unidade de demonstração ou parcela e responder a seguinte pergunta: Se fosse oferecido a você esse lote para utilizar a palha para o artesanato, você consideraria a textura da palha muito boa, boa, regular, ruim ou muito ruim ?. De acordo com as respostas obtidas, as parcelas foram classificadas seguindo escala de notas variando de 1 a 5 , sendo 1 atribuído às parcelas que produziram espigas com palha de textura muito boa para o artesanato e 5 àquelas com tex- tura muito ruim para o artesanato. Os caracteres altura de planta, comprimento de espigas e cor de palha foram avaliados em nível individual e os demais, no nível de média de parcelas.

Após as análises estatísticas, foram realizados os teste de médias e a análise conjunta, bem como estimado o coeficiente de determinação genotípica.

\section{Resultados e Discussão}

Na safra de 2002/2003, em Diamantina, a produtividade de espigas com palha em t/ha variou de 4,20, para a variedade MS016, a 7,25 para a variedade local 1 . Foram observadas elevadas produtividades também para as variedades MG092, BA073, MS031 e MS054 e elevada prolificidade para as variedades MG097, MS054, BA067, variedade local 1 e Saracura. Porém, na maioria dessas variedades, o maior número de espigas esteve associado ao menor comprimento de espigas, exceto no caso da variedade local 1 , que apresentou alta produtividade, associada a maior prolificidade e produção de espigas longas. O comprimento médio de espigas variou de $20,80 \mathrm{~cm}$, para a variedade Saracura, até 26,37 $\mathrm{cm}$, para a variedade MG088, destacando-se também as variedades MG082, MG092, BA093 e MG075. Quanto aos resultados observados para a coloração da palha, as variedades MG053 e BA100 destacaram-se pela maior variância entre espigas, que é considerada um fator positivo, pois a diversidade de cores é valorizada para a prática do artesanato. Quanto à textura de palha, determinada subjetivamente, destacaram-se as variedades MG092, MG093, MS031, MG075 e duas das variedades locais como os materiais aos quais foram atribuídas as melhores notas.

$\mathrm{Na}$ avaliação preliminar realizada em Cipotânea, na safra de 2002/2003, as produtividades de espigas com palha variaram de 3,35 t/ha, 
para a variedade PR013, até 7,90 t/ha, para o híbrido dublo BRS2020. Altas produtividades foram observadas também para as variedades MG092, SC015, Saracura e BR451. Quanto à prolificidade, destacaram-se a variedade MG097 e o híbrido BRS2020, porém, assim como em Diamantina, esses materiais tenderam a produzir espigas menores, o que não é útil para a prática do artesanato. $\mathrm{O}$ comprimento médio de espigas variou de $18,70 \mathrm{~cm}$, para a variedade BR451, até $25,78 \mathrm{~cm}$, para a variedade MG088, sendo, também, obtidos valores elevados para comprimento médio de espigas nas variedades MGIII e SC012. Para o estilo de artesanato praticado em Cipotânea, as variações de cores não são tão importantes quanto em Diamantina, pois apenas para alguns enfeites de peças é utilizada a palha colorida. Por essa razão, foram incluídos nessa avaliação um número maior de variedades de palha clara. Dessa forma, destacam-se as variedades BA143, MGIII, Composto Cristal, MS003, SC012, SC015, SP080, SC007, Saracura e BR451, assim como os híbridos BRS1010 e BRS2020, pela palha de cor clara e pela baixa variância entre espigas, para a nota de coloração de palha. Quanto à textura da palha, destacaramse as variedades MGIII e MS003.

Os resultados obtidos nas avaliações preliminares permitiram a caracterização inicial de acessos do Banco Ativo de Germoplasma de Milho quanto a caracteres da palha valorizados pelos artesãos. De acordo com as médias obtidas para os caracteres em questão e com a variabilidade observada dentro das populações na avaliação preliminar, foram selecionados os acessos MG088, BA093, MG075, SC012, SC015, MGIII, MG092, MG053, MS031 e MS003 para novas avaliações.

Os resumos das análises de variância e testes de médias realizados para o experimento implantado na comunidade de Planalto de $\mathrm{Mi}$ nas, em Diamantina, na safra 2003/2004, encontram -se na Tabela 1, pela qual é possível verificar que os acessos testados diferiam quanto à altura de planta, ao comprimento de espiga e à cor de palha, sendo obtidos, para essas características, baixos coeficientes de variação, indicando boa precisão do experimento. As variedades não diferiram quanto ao número de espigas e nota de textura de palha. O peso total de espigas por parcela não foi avaliado nessa condição ambiental, devido ao elevado ataque de pássaros, que comprometeu muito a produtividade. Dentre os caracteres para os quais os acessos diferiram, destacam-se as elevadas estimativas do coeficiente de determinação genotípico, indicando boa possibilidade de sucesso da seleção com base na manifestação fenotípica. A estimativa da elevada variância fenotípica dentro dos acessos indica a existência de grande potencial para a seleção intrapopulacional. Pelo teste de médias, foi possível verificar que as variedades testadas e a testemunha local tiveram médias de altura de planta superiores ao híbrido duplo BRS2020. As variedades MG088, SC012, SC015, MGIII destacaram-se devido ao maior comprimento de espiga. Entretanto, essas variedades produziram espigas maiores que as da testemunha local. Quanto à coloração da palha, foram encontradas diversas intensidades de coloração entre os acessos testados, sendo BA093, SC012, SC015, MGIII e MS003 e BRS2020 aqueles com menor intensidade de coloração de palha, enquanto o acesso MG053 apresentou alta pigmentação da palha.

Na Tabela 2, é apresentado o quadro com o resumo das análises de variâncias e teste de médias realizados a partir da avaliação conduzida em Paraopeba, na safra de 2003/2004. As variedades testadas diferiram quanto a altura de 


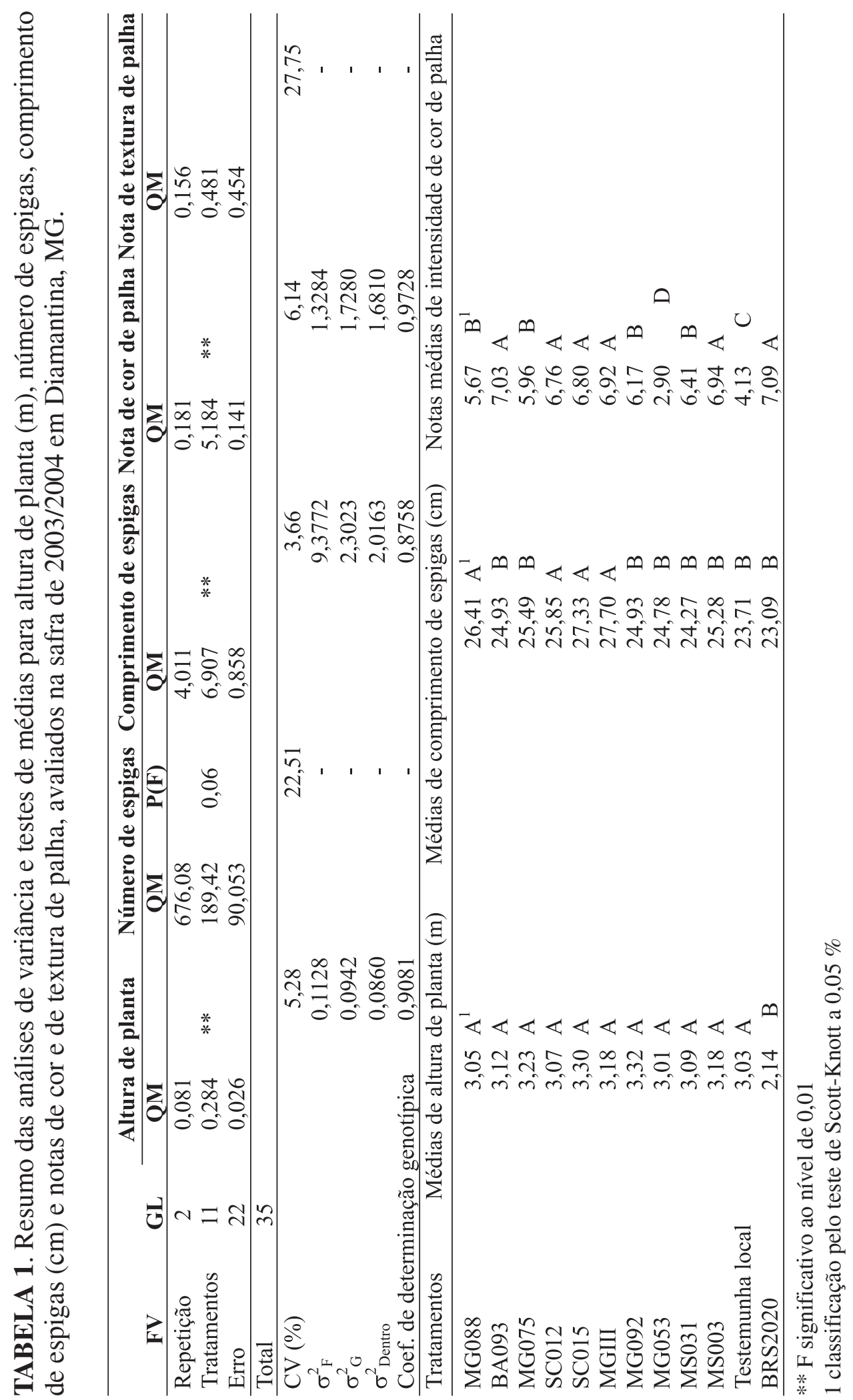




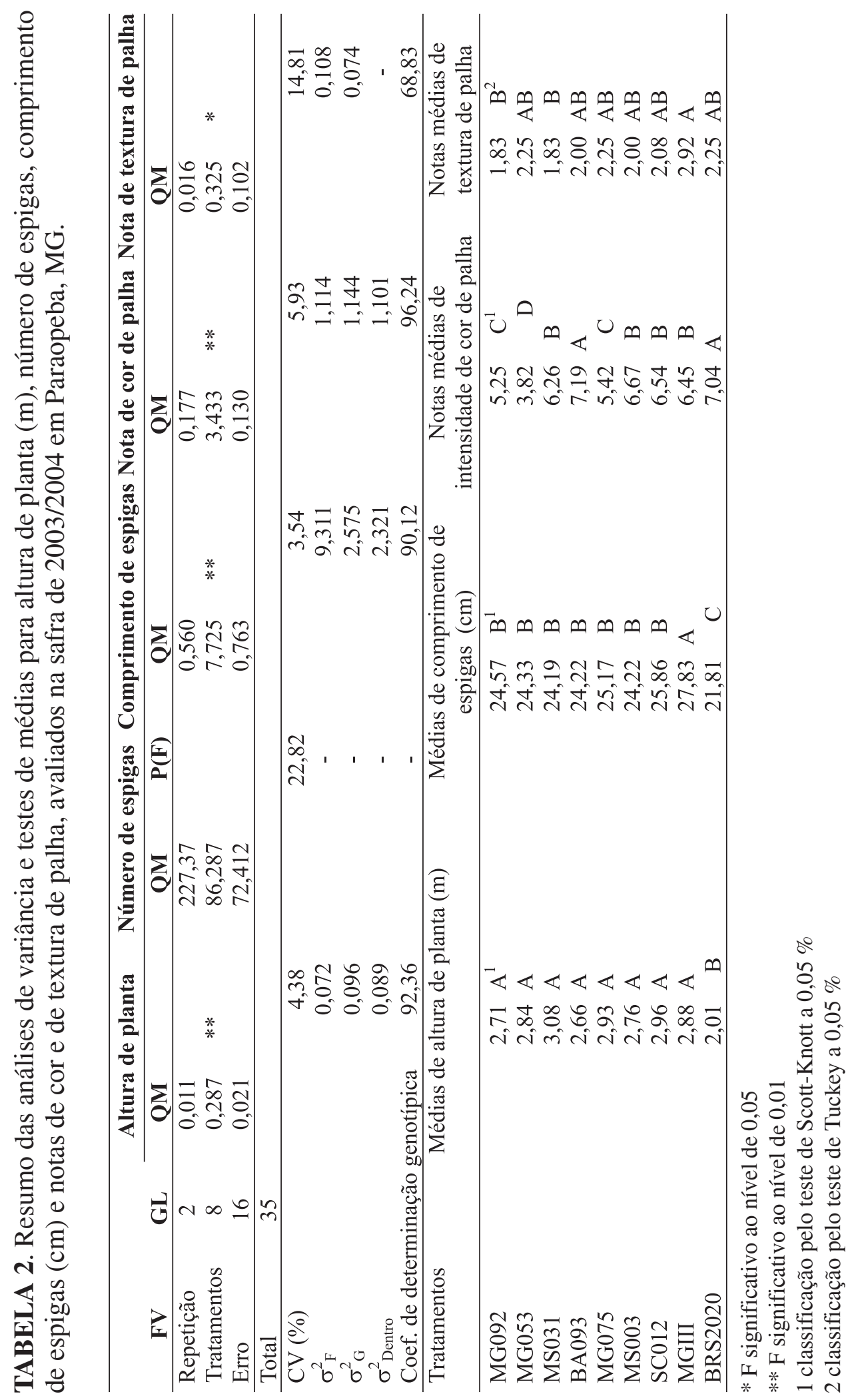

Revista Brasileira de Milho e Sorgo, v.6, n.1, p. 84-94, 2007 
planta, comprimento de espiga, notas de cor e textura de palha, que, apesar da dificuldade anterior, nesse caso, o coeficiente de variação foi baixo, indicando boa precisão experimental, assim como os obtidos para as demais características. O elevado coeficiente de determinação genotípico estimado sugere que a seleção com base na manifestação fenotípica é promissora. A alta variação fenotípica dentro das populações, para os caracteres altura de planta, comprimento de espiga e nota de cor de palha, confirmam a possibilidade de sucessos com a seleção intrapopulacional. Todas as variedades testadas apresentaram médias de altura de planta superiores ao híbrido duplo BRS2020, confirmando o porte elevado desses acessos, o que pode levar ao maior percentual de plantas acamadas. Quanto ao tamanho da espiga com palha, destacou-se a variedade MGIII. As demais variedades não melhoradas foram classificadas em um mesmo grupo, com tamanho de espiga intermediário entre a variedades MGIII e o híbrido BRS2020. Quanto à textura de palha, destacaram-se as variedades MG092 e MS031.

Foram realizadas as análises conjuntas e testes de médias para altura de planta, comprimento de espigas e nota de cor de palha, considerando os resultados obtidos nos experimentos conduzidos na safra de 2003/2004, em Diamantina e Paraopeba (Tabela 3). Para esses caracteres, foram estimados quadrados médios de tratamentos muito elevados, em comparação com os quadrados médios estimados para os fatores ambiente e interação ambientes por tratamentos. Porém, o efeito do ambiente influenciou a manifestação da altura de planta, sendo o porte médio das plantas muito mais elevado em Diamantina do que em Paraopeba, na safra de 2003/2004. Já para a nota da cor de palha, foi observada a interação genótipo por ambientes, porém, é possível verificar, no teste de médias, que a interação promoveu apenas pequenas alterações na classificação das variedades. De acordo com os resultados obtidos com o teste de médias, o acesso MGIII apresentou espigas maiores que os demais, porém, esses produziram espigas maiores que híbrido duplo BRS2020, utilizado como testemunha. Para a altura de plantas, o teste realizado com as médias das análises conjuntas mostrou que os acessos avaliados tiveram desempenho semelhante entre si, porém produziram plantas maiores que o híbrido duplo BRS2020.

Os resultados obtidos permitiram identificar os acessos MS003, MS032, BA093, SC012, SC015, MG053, MG075, MG088, MG092 e MGIII para futuros cruzamentos com materiais elite de baixo porte do programa de melhoramento de milho da Embrapa Milho e Sorgo, visando obter populações que aliem palha com qualidade para artesanato a baixo porte de planta. Essas populações serão selecionadas nas comunidades que se dedicam ao artesanato com palha de milho, para que a seleção para desempenho agronômico seja feita sob as condições ambientais em que as populações serão cultivadas, e para que as artesãs façam a seleção de espigas com palha apropriada para o artesanato.

A seleção nas populações segregantes deverá ser feita com a participação das artesãs que tenham prática com o trabalho artesanal com a palha de milho, nas respectivas comunidades onde serão cultivadas as variedades obtidas nesse programa de melhoramento. Deve ser considerado que, apesar de não terem sido identificadas interações genótipos por ambientes para o comprimento de espigas, cor de palha e altura de planta, a interação genótipos por ambientes para a produtividade de grãos costuma ser alta (Gonçalves et al., 1999; Carvalho et al., 2000; Gama et al., 2000; Carvalho et al., 2001). 


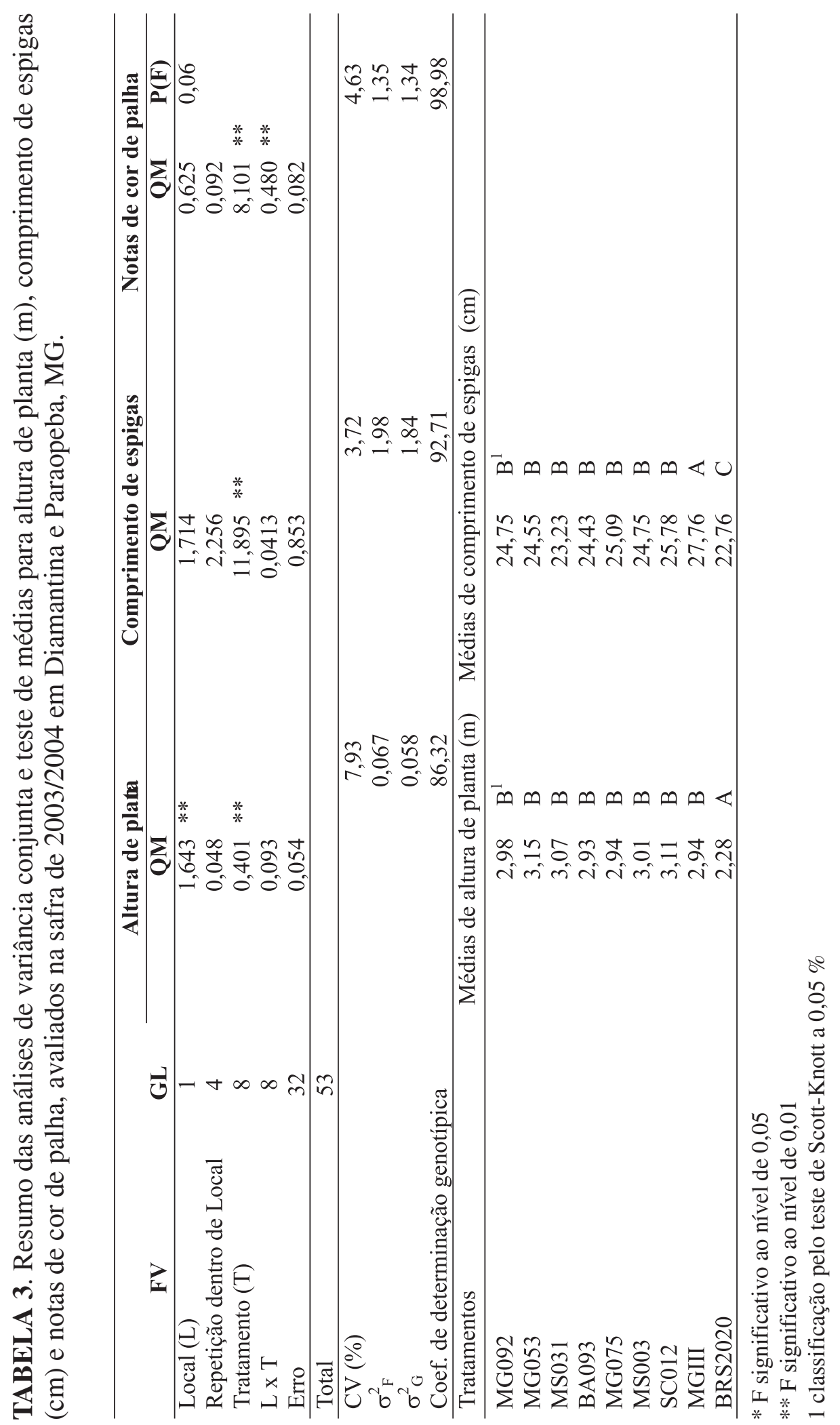

Revista Brasileira de Milho e Sorgo, v.6, n.1, p. 84-94, 2007 


\section{Conclusões}

A avaliação da textura da palha, devido a sua subjetividade, apresentou resultados associados a altos coeficientes de variação e a altas probabilidades de $\mathrm{F}$, o que leva à necessidade do desenvolvimento de métodos para avaliação dessa característica com maior precisão. Os coeficientes de determinação genotípica estimados apresentaram valores elevados, indicando o potencial da seleção com base na manifestação fenotípica. A variância dentro das populações estimada indicou a possibilidade de sucesso com a seleção intrapopulacional.

\section{Agradecimentos}

Os autores agradecem o apoio e o incentivo da Fundação Instituto Centro Cape, do Ministério do Desenvolvimento Agrário, do Ministério da Ciência e Tecnologia, da Empresa de Extensão Rural do Estado de Minas Gerais e da Associação de Artesãs dos Municípios de Cipotânea e de Diamantina.

\section{Literatura Citada}

ANDRADE, R.V.; FILHO, I.A.P.; SANTOS, M.X.; FRANCISCO, R.S.S.; LEITE, C.E.P. Banco ativo de germoplasma de milho. III Sirgealc. Anais do III Simpósio de Recursos Genéticos para a América Latina e Caribe. Londrina, 2001.

ARTE que vem da terra. Estado de Minas, Belo Horizonte, 14 jul. 2003. Caderno Agropecuario, p. 12.

CANAL RURAL. Programa Técnica Rural.. Artesanato com a palha do milho. Técnica Rural. Canal Rural. 16 jun. 2003. TV

CARVALHO, H. W. L.; LEAL, M. L. S.; SANTOS, M. X.; CARDOSO, M. J.; MONTEIRO,
A. A. T.; TABOSA, J. N. Adaptabilidade e estabilidade de cultivares de milho no Nordeste brasileiro no ano agrícola de 1988. Pesquisa Agropecuária Brasileira, Brasília, DF, v. 35, n. 6, p. 1115-1123, 2000.

CARVALHO, H. W. L.; LEAL, M. L. S.; CARDOSO, M. J.; SANTOS, M. X.; CARVALHO, B. C. L.; TABOSA, J. N.; LIRA, M. A.; ALBUQUERQUE, M. M. Adaptabilidade e estabilidade de cultivares e híbridos de milho no Nordeste brasileiro. Pesquisa Agropecuária Brasileira, Brasília, DF, v. 36, n. 4, p. 637-644, 2001.

CIMMYT. Descriptors for maize. Rome: CIMMYT / IBPGR, 1991. 88 p.

GAMA, E. E. G.; PARENTONI, S. N.; PACHECO, C. A. P.; OLIVEIRA, A. C.; GUIMARÃES, P .E. O.; SANTOS, M. X. Estabilidade da produção de germoplasma de milho avaliado em diferentes regiões do Brasil. Pesquisa Agropecuária Brasileira, Brasília, DF, v. 35, n. 6, p. 1143-1149. 2000.

GONÇALVES, F. M. A.; CARVALHO, S. P.; RAMALHO, M. A. P.; CORREA, L. A. Importância das interações cultivares $\mathrm{x}$ locais e cultivares $\mathrm{x}$ anos na avaliação de milho na safrinha. Pesquisa Agropecuária Brasileira, Brasília, DF, v. 35, n. 7, p. 1175-1181. 1999.

MIL e uma utilidades. Globo Rural. Rio de Janeiro: Rede Globo, 14 de novembro de 1994. Programa de TV.

MORRIS, M. L.; BELLON, M. R. Participatory plant breeding research: Opportunities and challenges for the international crop improvement system. Euphytica, Wageningen, v. 133, p. 2135, 2004. 
TEIXEIRA, F.F.; VASCONCELOS, J.H.; MON- to a palha para artesanato. IV Sirgealc. Anais do TEIRO, M.A.;ANDRADE, R.V. Avaliação de IV Simposio de Recursos Genéticos para Amériacessos do banco de germoplasma de milho quan- ca Latina y el Caribe. p. 135. Mar del Plata, 2003. 